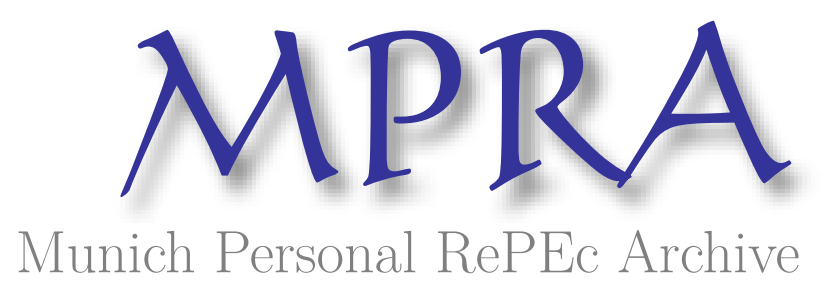

\title{
The divide-and-conquer and employer/employee models of discrimination: neoclassical competition as a familial defect
}

Mason, Patrick L.

1992

Online at https://mpra.ub.uni-muenchen.de/11333/

MPRA Paper No. 11333, posted 03 Nov 2008 10:51 UTC 


\title{
THE DIVIDE-AND-CONQUER AND EMPLOYER/ EMPLOYEE MODELS OF DISCRIMINATION: NEOCLASSICAL COMPETITION AS A FAMILIAL DEFECT
}

\begin{abstract}
Patrick L. Mason
This article is an examination of the similarities between Michael Reich's divide-and-conquer model of discrimination and the BeckerArrow taste model of discrimination. It shows that Reich's model of discrimination is analytically identical to Arrow's employer discrimination model when employer utility is a function of total profits and the racial employment ratio. It also shows that the Becker-Arrow distinction between employer and employee discrimination is invalid. Finally, the author argues that neoclassical competition is the major defect of both models. After discussing the implications of these results the article points to new directions in the literature on the economics of discrimination.
\end{abstract}

Does the divide-and-conquer model of discrimination offer any insights into the relationship between racial discrimination and the competitive process that are substantively different from the neoclassical model of discrimination? No, it does not. Becker and Arrow provide the classic references to orthodox models of discrimination. ${ }^{1}$ They reached three general conclusions: (1) employer discrimination is not consistent with perfect competition, although some forms of employee discrimination may be consistent with long-run equilibrium under perfectly competitive conditions; (2) employers do not gain from discrimination, although some subgroups of workers may be better off; and (3) employer discrimination will persist only in those areas of the economy which are protected from the equalizing forces of competition. Reich's divide-and-conquer model 